\title{
Extraction of Lignin from Empty Fruit Bunch Fiber via Microwave-Assisted Deep-Eutectic Solvent Heating
}

\author{
I.S. Muryadi1 ${ }^{*}$, M.N.A. Yaakob ${ }^{1}$, R. Roslan ${ }^{1}$ \\ ${ }^{1}$ Faculty of Industrial Science and Technology, Universiti Malaysia Pahang, 26600 Pahang, Malaysia.
}

\begin{abstract}
This work study about the extraction of lignin from Empty Fruit Bunch (EFB). It is a type of lignocellulosic waste produced during the palm oil extraction process. There are three main components of lignocellulosic, which is one of them is lignin. A deep eutectic solvent (DES) with microwave-assisted heating has been used as a process to extract the lignin from EFB and turn it into a value-product. This convenient method was started with the mixing of EFB and DES. After that, the mixture was heated via microwave synthesis reactor at different temperature and time parameters. The extracted lignin yield was dried and ground into a powder form. The highest lignin yield recovered is $30 \%$ by the highest time and temperature. Interestingly, the purity of all lignin yields are above than $80 \%$. The highest yield of lignin was characterized. According to FourierTransform Infrared (FTIR) spectra, there was a significant functional group of phenolic and aliphatic hydroxyl in lignin. Besides, the methoxy group was also configured in lignin spectra. The presence of conjugated alkene also conveyed the characteristic of lignin. The FTIR spectra were intensified with ${ }^{1} \mathrm{H}$ Nuclear Magnetic Resonance (NMR) spectra where there was a chemical shift in lignin and raw EFB which was designated to aliphatic and aromatic protons bonded to a carbon atom. Three regions of decomposition occur in the Thermogravimetric Analysis (TGA) spectra. The initial decompose temperature of lignin was lower compare to raw EFB. Next, second-stage lignin decomposed at $434.14{ }^{\circ} \mathrm{C}$ with weight loss of $36.21 \%$. Lastly, for the final stage, lignin decomposes at $552.54{ }^{\circ} \mathrm{C}$. Moreover, Differential Scanning Calorimetry (DSC) spectra demonstrate that the $\mathrm{Tg}$ value of lignin managed to be identified. However, the $\mathrm{Tg}$ value of raw EFB cannot be well defined. As for the characterization in residual fractions of EFB, the lowest crystallinity index ( $\mathrm{Crl}$ ) value of raw EFB has proven the presence of lignocellulosic in its structure. The residual fractions that reacted at higher temperatures have an inflated value of $\mathrm{Crl}$ as they contain abundant left out cellulose.
\end{abstract}

\section{ARTICLE HISTORY}

Received: $26^{\text {th }}$ July 2021

Revised: $25^{\text {th }}$ Aug 2021

Accepted: $13^{\text {th }}$ Oct 2021

\section{KEYWORDS}

Deep Eutectic Solvent

Empty Fruit Bunch

Lignin

Microwave-assisted

\section{INTRODUCTION}

The major solid waste in palm oil mils processing is an empty fruit bunch (EFB), fibers, and oil palm shells. Palm oil mils produce about 14\% fibers, $7 \%$ shells, and 23\% EFB per ton of fresh fruit bunch (FFB) [1]. Annually, approximately 15 million tons of EFB waste is produced [2], resulting in an EFB dump that created a major disposal problem. The short path to eliminate the wastes is by burned off, which can cause harm to the environment and social aspect. To achieve environmentally friendly production while maximizing profit, EFB must be utilized to generate high value-added products. EFB is a kind of lignocellulosic waste generated during the palm oil extraction process and is a renewable raw material resource. There are three main components of lignocellulose, i.e. (i) cellulose, (ii) hemicellulose, and (iii) lignin. Lignin is usually the least utilized among lignocellulose major constituents [2].

Extraction technology is a critical step to isolate the main component of lignocellulose before upgrading onto high value-added products. There are varieties of lignin extraction methods, such as physical, chemical, biological, or the combination of those methods implemented and published [3]. Before this, traditional extraction methods such as kraft, lignosulfonates, soda, organosolv, and ionic liquid have been widely practiced and shown their advantage. Nevertheless, those methods was also showed some deficiencies, such as required long reaction time during the lignin extraction process, ineffective cost, and low amount of lignin extracted. In this modern era, DES was able to replace ionic liquids (ILs) by achieving green solvents that have similar physiochemical like its. Recently, DESs have established their powerful abilities in the pretreatment of lignocellulose. Many groups have applied DESs into the extraction trials and came out with good results [4]. In this work, DESs are used to enhance the extraction of lignin from EFB by mixing dicarboxylic acid (oxalic acid) with choline chloride via microwave-assisted heating.

Among the technologies used, the microwave-assisted process has proven to be promising to pretreat biomass due to less time required for the process. This technology also lowers the severity of ionic liquid and alkaline pretreatments. The ability of ease of control the reaction conditions, fast and selective heating, low reaction temperature, 
and low energy requirements are additional advantages of using microwave radiations[3]. Previous research has proved that microwave-assisted heating is successfully applied to wood pretreatment. Compared to conventional heating, it was able to extract a large amount of lignin. Microwave-assisted DES pretreatment has allowed $80 \%$ lignin extracted from wood in just 3 min reaction time [5]. However, using conventional heating, choline chloride: oxalic acid needs at least 9 $\mathrm{h}$ at $110^{\circ} \mathrm{C}$ to achieve the same amount of lignin. In this work, the EFB extraction will be conducted with a microwave to extract a high amount of lignin like wood. This approach valorizes the available biomass, for example, modified lignin into UV-curable coating since lignin has an ultraviolet (UV)-absorbing property which is suitable to be used as coatings.

DES are used via microwave-assisted heating which can reduce time and energy due to the microwave radiations during the extraction process. Therefore, this study aims to extract the lignin yield utilizing DES via microwave-assisted heating. Then, the yield and purity of lignin will be calculated according to TAPP1 and NREL standards. The residual EFB was also investigated based on their crystallinity index. The scope of this work is to find the amount of lignin yield for each sample and characterize the highest lignin yield recovered using FTIR, TGA, DSC, and NMR. As for the residual fractions of EFB for all samples was characterized using XRD.

\section{MATERIALS AND METHODS}

\section{Materials}

Materials used in this study are EFB fibers (Szetech Sdn Bhd), deionized water, toluene (ACS reagent 99.5\%), absolute ethanol, acetone (ACS reagent 99.5\%), choline chloride (Reagent grade 98\%), and oxalic acid (Reagent grade $98 \%$ ).

\section{Methodology}

\section{Pre-treatment of EFB Fibers}

Initially, the EFB fibers wash regularly with deionized water to ensure its free from dirt, dust, and impurities on the fiber surface and dry under direct sunlight. The dried fibers were grounded into a powder with a commercial cutting mill (Retsch SM100). The oil and wax components from the EFB were removed using soxhlet extraction with toluene: ethanol (2:1) mixture for $7 \mathrm{~h}$. Then, the extractive-free dewaxed fibers were washed using deionized water to remove the excess soxhlet solvent, dry at $105{ }^{\circ} \mathrm{C}$, and store in a dry cabinet for further use. The EFB powder was characterized to identify alpha-cellulose, extractives/fat, ash, moisture, and lignin, based on TAPP1 T203, T204, T211, T421, and T222.

\section{Lignin Extraction from EFB Fiber Using Microwave-Assisted Heating}

DES process was utilized in the extraction of lignin from EFB fibers. The DES was prepared by mixed chlorine chloride as a hydrogen bond acceptor (HBA) and oxalic acid as a hydrogen bond donor (HBD) with a molar ratio of 1:1. The mixture was mixed under reduce pressure at $90{ }^{\circ} \mathrm{C}$ until a transparent solvent form. The lignin extraction from EFB fiber was performed by using microwave-assisted heating. The EFB fiber with an amount of $20 \mathrm{~g}$ will be mixed with 200 $\mathrm{g}$ DES. The mixture was reacted in a microwave synthesis reactor. The temperature will be raised from room temperature to $80{ }^{\circ} \mathrm{C}$ in between $2 \mathrm{~min}$ and held at the temperature for $5 \mathrm{~min}$. Once the reaction is completed, the dark-brown liquid was mixed with $200 \mathrm{~mL}$ acetone: water $(1: 1 \mathrm{v} / \mathrm{v})$ and filtered by vacuum filtration to isolate the soluble and insoluble DES fractions. The acetone in the filtrate was evaporated using a rotary evaporator and form black liquor, while the lignin was precipitated and collected through centrifugation. Lastly, the lignin sample was dried at $45{ }^{\circ} \mathrm{C}$ in an oven for $12 \mathrm{~h}$ and placed in a glass vial at room temperature. For the optimization, the reaction was repeated with different temperatures $(80$ ${ }^{\circ} \mathrm{C}, 90^{\circ} \mathrm{C}$, and $100{ }^{\circ} \mathrm{C}$ ) and times $(10 \mathrm{~min}, 20 \mathrm{~min}$, and $30 \mathrm{~min})$.

\section{Percentage of Yield and Purification Lignin}

$$
L(\%)=\frac{m_{\text {isolated }}}{m_{\text {TAPPI }}} \times 100 \%
$$

Where $\mathrm{L}$ is crude lignin yield $(\%) ; \mathrm{m}_{\text {isolated }}(\mathrm{g})$ is the mass of lignin isolated in microwave-assisted heating and $\mathrm{m}_{\text {TAPPI }}(\mathrm{g})$ is the mass of lignin calculated using TAPPI method.

The yield of lignin produced after microwave-assisted heating was calculated using TAPPI T222. In short, 0.03 $\mathrm{g}$ of lignin was treated with $1.2 \mathrm{~mL}$ of $\mathrm{H}_{2} \mathrm{SO}_{4}(67 \mathrm{wt} \%)$ at room temperature for $24 \mathrm{~h}$. The mixture was placed in an ultrasonic water bath for $1 \mathrm{~h}$ at $30{ }^{\circ} \mathrm{C}$. The mixture was located in the autoclave at $1 \mathrm{~h}$ at $102{ }^{\circ} \mathrm{C}$. By using vacuum filtration, the acid-insoluble excess was isolated, and the excess was washed with deionized water until it reaches neutral 
$\mathrm{pH}$ followed by 24 hour drying at temperature $105^{\circ} \mathrm{C}$. The acid-soluble lignin was determined using the first filtrate acquired in the lignin that is soluble in acid. The filtrate would be 4 wt \% diluted. $\mathrm{H}_{2} \mathrm{SO}_{4}$ with a ratio of $1: 10$ (v / v) and acid-soluble lignin were counted at $240 \mathrm{~nm}$ from the UV absorbance. The overall amount of acid-insoluble and acidsoluble lignin was decided as the amount of the sample purity lignin content.

\section{Washing the Residual Fractions}

The residual obtained after isolation of lignin was wash repeatedly using deionized water and acetone with a ratio $1: 10(\mathrm{v} / \mathrm{v})$ by using a hot plate. Then, the residual fractions were dried by using the oven at $90{ }^{\circ} \mathrm{C}$. The dried residual was ground by using mortar and pestle until it turns into powder form.

\section{Characterization of Lignin and Residue EFB.}

The 1D- ${ }^{\mathrm{H}} \mathrm{NMR}$ were recorded with Nuclear Magnetic Resonance (NMR) spectrometer (Bruker, 500MHz), using deuterated dimethylsulfoxide (DMSO-d6) as a solvent. The lignin was dissolved in $1.0 \mathrm{~mL}$ of DMSO-d6 and the solvent peak was used as an internal reference (DMSO H 2.50). The spectra were processed for their coherent alignment, spectral phasing, calibration, baseline correction, and integration through TopSpin software. Meanwhile, Computer-Assisted Structure Eludication in MestreNova 14.0.0 was used to illustrated the NMR spectra. FTIR analysis was used the powder of lignin by put in the cassette and placed in the light path. Spectra analysis was performed on a Perkin Elmer Spectrum 100 FTIR Spectrometer with Potassium Bromide (KBr) disk method and $4 \mathrm{~cm}^{-1}$ resolution at the $4000-700 \mathrm{~cm}^{-1}$ wavenumber range [6]. TGA was performed using the TGA Q500 TA instrument. Approximately $15 \mathrm{mg}$ of the samples was weighed and heated from 25 to $600{ }^{\circ} \mathrm{C}$ at a heating rate of $10^{\circ} \mathrm{C} / \mathrm{min}$ under a nitrogen flow of $40 \mathrm{~mL} / \mathrm{min}$. DSC were be performed on a NETZSCH DSC 214-Polyma, under the $\mathrm{N}_{2}$ atmosphere with a flow rate of $50 \mathrm{~mL} / \mathrm{min}$. Approximately $10 \mathrm{mg}$ samples were weighed in an aluminum crucible and heated from $25-300{ }^{\circ} \mathrm{C}$ at a heating rate of $10{ }^{\circ} \mathrm{C} / \mathrm{min}$. The residual fractions were characterized by X-ray Diffractometer (XRD) (Rigaku Miniflex II). The X-ray diffractometer was utilized $\mathrm{Cu} \mathrm{K} \alpha$ radiation with wavelength $1.5460 \AA$ and Nickel, Ni filter; with an accelerating voltage of $30 \mathrm{kV}$ and cathodic current of $15 \mathrm{~mA}$ under a wide range of $2 \theta$ Bragg angles $\left(10^{\circ} \leq 2 \theta \leq 60^{\circ}\right)$ at a scanning rate of $2^{\circ} / \mathrm{min}$.

\section{RESULT AND DISCUSSION}

\section{Percentage of yield and purity of lignin}

As shown in Table 1 and Figure 1, the highest yield of isolated lignin extracted using DES via microwave-assisted heating is $30 \%$. The presence of acidic strength from oxalic acid in DES pretreatment has enhanced hydrogen accepting bond. As the temperature ramp, the yield recovered was also increase. This indicates that there was a breakage of hydrogen bonds in EFB fibers via microwave-assisted at elevated temperature during the extraction. However, the excessive temperature will result in less isolation lignin due to condensation that influences less solubility lignin in DES. In terms of reaction time, the prolonged reaction time has raised lignin's yield, strengthening the plant cell wall, allowing the lignin macromolecules in EFB to split into tiny lignin fractions in the DES solution [7]. The DES complied with acid hydrogen bond donor (HBD) which succeeded in the extraction of lignin from EFB fibers. Moreover, microwave irradiation may increase the ion characteristic, thus raising the molecular polarity of DES [8]. The purity of lignin different regarding their temperature and time of reaction. Overall purity of lignin yield achieves higher than $80 \%$.

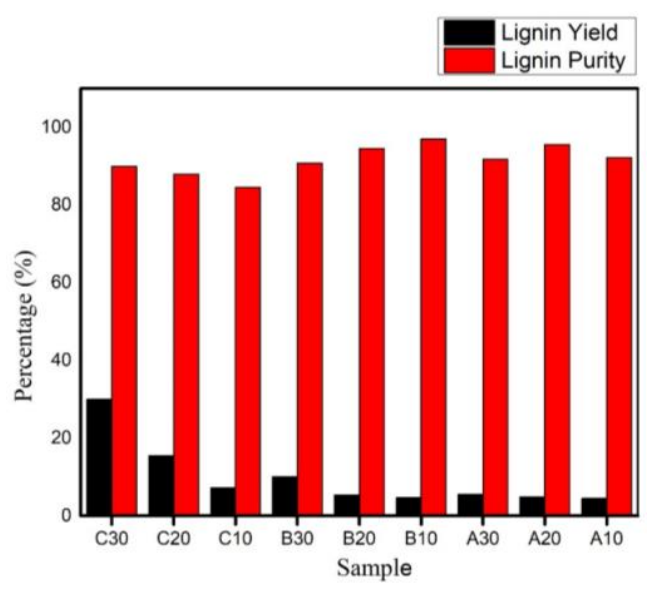

Figure 1. Yield and purity of lignin under divergent temperature and time 
1

Table 1. Yield and purity of lignin recovered

\begin{tabular}{ccccc}
\hline Sample & $\begin{array}{c}\text { Reaction } \\
\text { Time }(\min )\end{array}$ & $\begin{array}{c}\text { Reaction Temperature } \\
\left({ }^{\circ} \mathrm{C}\right)\end{array}$ & $\begin{array}{c}\text { Lignin yield } \\
(\%)\end{array}$ & $\begin{array}{c}\text { Purity of } \\
\text { lignin }(\%)\end{array}$ \\
\hline C30 & 30 & 100 & 30 & 89.94 \\
C20 & 20 & 100 & 15.44 & 87.96 \\
C10 & 10 & 100 & 7.17 & 84.52 \\
B30 & 30 & 90 & 10.07 & 90.74 \\
B20 & 20 & 90 & 5.44 & 94.53 \\
B10 & 10 & 90 & 4.64 & 96.93 \\
A30 & 30 & 80 & 5.51 & 91.84 \\
A20 & 20 & 80 & 4.93 & 95.55 \\
A10 & 10 & 80 & 4.44 & 92.17 \\
\hline
\end{tabular}

\section{Structural Characterization of Highest Lignin Yield}

\section{Fourier-Transform Infrared Spectroscopy (FTIR)}

According to the FTIR spectra displayed in Figure 2, a broadband at $3417.91 \mathrm{~cm}^{-1}$ and $3437.61 \mathrm{~cm}^{-1}$ was detected representing strong intermolecular force bonding of a stretching vibration between phenolic and aliphatic hydroxyl which abundant in the extracted lignin and raw EFB. At $2930.55 \mathrm{~cm}^{-1}$ and $2846.85 \mathrm{~cm}^{-1}$ on lignin spectra while at $2937.38 \mathrm{~cm}^{-}$ ${ }^{1}$ in raw EFB spectra which both attributes to $\mathrm{C}-\mathrm{H}$ stretching vibrations of methyl groups. The presence of stretching vibration of alkene group at $1638.28 \mathrm{~cm}^{-1}$ in raw EFB. Moving to lignin fractions, at $1605.68 \mathrm{~cm}^{-1}$ there was presence of stretching vibration of $\mathrm{C}=\mathrm{C}$ conjugated alkene, which generally in lignin functionalities [9]. The presence of aromatic skeletal vibrations was shown from $1605.68 \mathrm{~cm}^{-1}$ to $1466.10 \mathrm{~cm}^{-1}$. In addition, there were phenylpropane signals detected in the lignin structure at $1293.42 \mathrm{~cm}^{-1}$ stretching vibrations of C-O aromatic ester. Hardwood lignin contains a mixture of guaiacyl (G) and syringyl (S) where lignin spectra in Figure 3 show the $\mathrm{C}-\mathrm{O}$ stretching vibrations in syringyl units (S) approximately at $1293.42 \mathrm{~cm}^{-1}$ while raw EFB at $1254.76 \mathrm{~cm}^{-1}$ [10], Two adjacent signals at $1228.99 \mathrm{~cm}^{-1}$ and 1131.22 $\mathrm{cm}^{-1}$ were attributed to the deformation of ester bonds. On the other hand, the existence of guaiacyl structure (G) also presents on that signal. Raw EFB spectra contain broadband at $1047.09 \mathrm{~cm}^{-1}$ meanwhile in the lignin spectra at peak $1131.22 \mathrm{~cm}^{-1}$ shown the primary alcohol. Lastly, at $890.95 \mathrm{~cm}^{-1}$ of raw EFB spectra, there are bending vibrations of alkene.

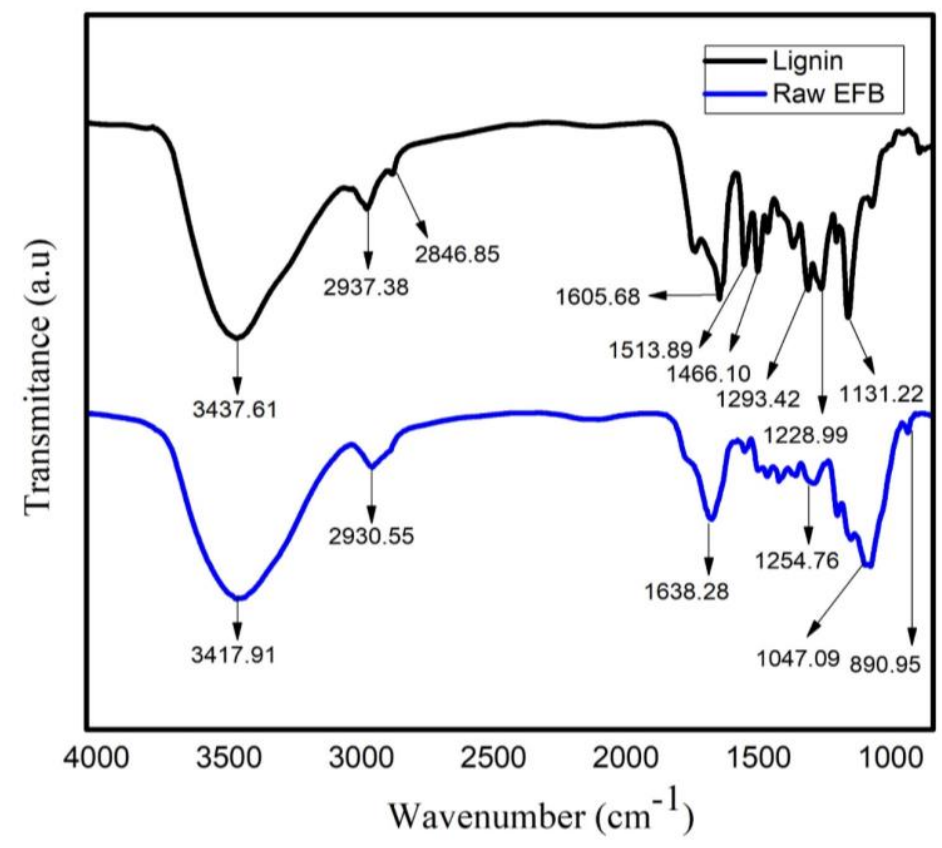

Figure 2. FTIR spectra of lignin yield and raw EFB 


\section{Thermogravimetric Analysis (TGA)}

According to Figure 3, there are three regions of weight loss in which the sample started to decompose. The initial temperature was the evaporation of water and moisture from each sample. Then, the decomposition initiated in the sample detected around $230.72{ }^{\circ} \mathrm{C}$ in lignin and $256.28{ }^{\circ} \mathrm{C}$ in raw EFB where there was a cleavage of $\alpha$ - or $\beta$-aryl-alkyl ether bonds [10]. In the first stage, the weight loss approximately drops from $99 \%$ to $92.80 \%$ in lignin, slightly different from raw EFB $(86.16 \%)$. It was obvious a broad and smooth shoulder was observed instead of a peak due to the low degradation temperature fragmented by the hydrogen bonding present in DES that causing low degradation. Up to 150 ${ }^{\circ} \mathrm{C}$, DES has influenced the stability of lignin which proves DES suitable for the EFB extraction method [3]. Besides, the thermogravimetric revealed that acetone and water extracted lignin dominate excessive stability below $300{ }^{\circ} \mathrm{C}$ were known as one of lignin factor. Move to the second stage in lignin at $434.14{ }^{\circ} \mathrm{C}$ with approximately $36.21 \%$ weight loss of lignin contradict to raw EFB where the weight loss is $41.53 \%$ at $359.29^{\circ} \mathrm{C}$. The lignin particle required a high amount of energy to decompose at a high temperature compared to raw EFB. As for the third stage, the lignin decomposes at $552.54^{\circ} \mathrm{C}$ meanwhile raw EFB at $546.41^{\circ} \mathrm{C}$. However, the degradation continues until both samples turn into ash.

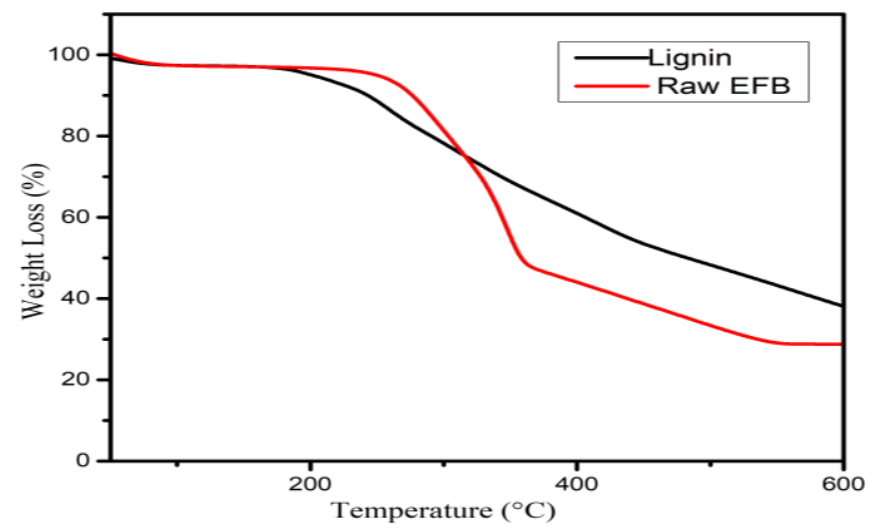

Figure 3. TGA graph of lignin yield and raw EFB

\section{Differential Scanning Calorimetry (DSC)}

DSC was utilized to detect the glass transition $\left(T_{g}\right)$ temperature of lignin and raw EFB. $T_{g}$ can be defined as the temperature where the polymer substrate transforms from a rigid glassy into a soft substance. According to the thermogram in Figure 4, $\mathrm{T}_{\mathrm{g}}$ value, the lignin substance is in a glassy state where the structure is amorphous while between the $\mathrm{T}_{\mathrm{g}}$ value, its turn into a rubbery state [11]. The removal of moisture and water occurs below $30^{\circ} \mathrm{C}$. When temperature ramp, reaction initiates approximately at $100{ }^{\circ} \mathrm{C}$. Normally the value of $\mathrm{T}_{\mathrm{g}}$ begins from $110{ }^{\circ} \mathrm{C}$ to $200{ }^{\circ} \mathrm{C}$. $\mathrm{T}_{\mathrm{g}}$ value of lignin is $195{ }^{\circ} \mathrm{C}$ while there is no difference in residue EFB thermogram due to the strong intermolecular force of the molecule in EFB structure consist of cellulose, hemicellulose, and lignin [12]. Lignin typically different comparing the other two substitutes in EFB due to its packed propane units interconnected in a complex amorphous matrix. Other than that, the amorphous state has caused the $\mathrm{T}_{\mathrm{g}}$ not analyzed in well defined [13].

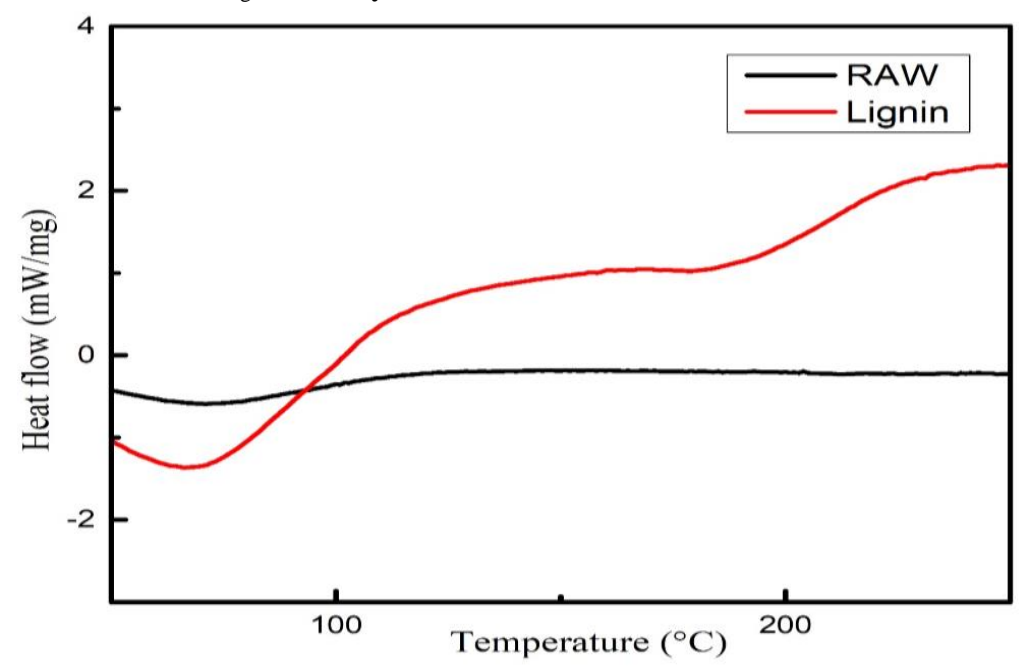

Figure 4. DSC thermogram of lignin yield and EFB raw 


\section{Nuclear Magnetic Resonance (NMR)}

${ }^{1} \mathrm{H}$ NMR was studied by using DMSO as a solvent. However, the lignin was not completely dissolved. The ${ }^{1} \mathrm{H}$ NMR spectra, illustrated in Figure 5 was used to identify the lignin structure and prove the linkage presence in FTIR spectra. The signal observed in lignin spectra as shown in Figure 5(iii) around $6.5 \mathrm{ppm}$ represented an aromatic proton in guaiacyl and syringyl shifts while there is no peak in raw EFB spectra [14]. Moreover, the chemical shifts at 1.26 ppm assigned to aliphatic and aromatic protons bonded to a carbon atom which present in raw EFB spectra, while lignin only has aliphatic protons [15]. The same aliphatic protons were represented in lignin structure in EFB fibers, Figure 5 (i) [16]. However, raw EFB has a lower peak compare to lignin because of the limited amount of lignin in the EFB fiber. The chemical shifts in Figure 5 (ii) between $5.0 \mathrm{ppm}$ represent benzylic $\mathrm{H}$ in lignin structure. Next, at $2.52 \mathrm{ppm}$ both spectra have peaks constituted to solvent peak in Figure 5 (iv).

(i)

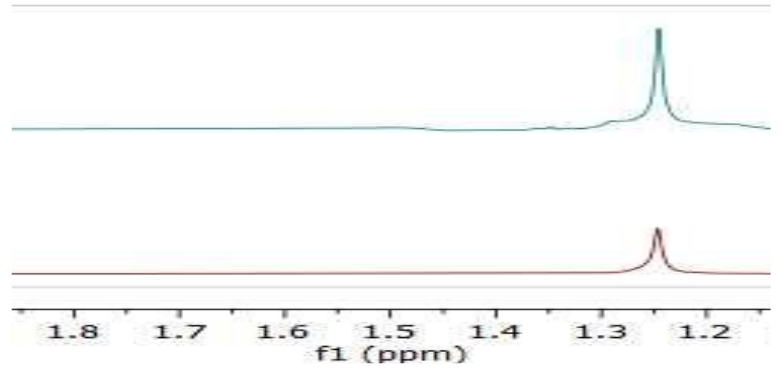

(iii)

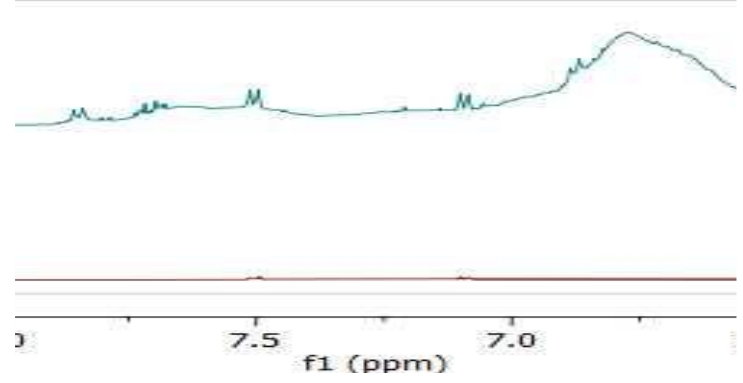

(ii)

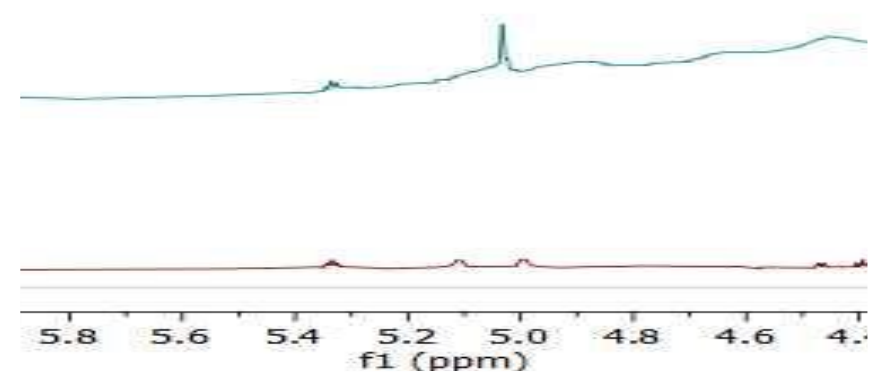

(iv)

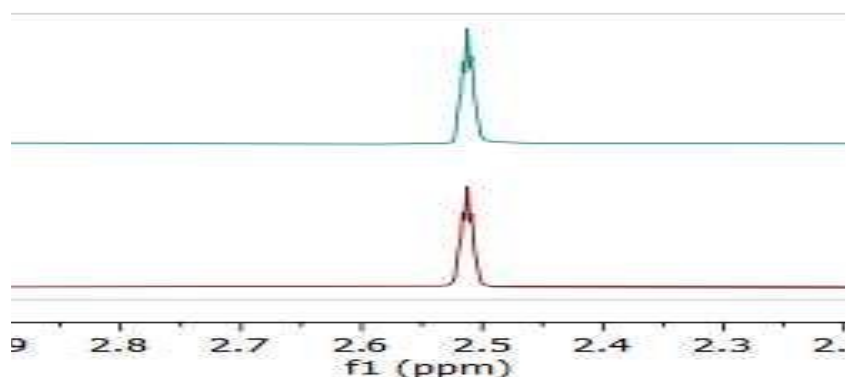

Figure 5. 1D- ${ }^{\mathrm{H} N M R}$ spectra of raw EFB and Lignin

\section{Characterization of Residual Fractions}

\section{$X$-ray Diffraction (XRD)}

The crystallinity Index $(\mathrm{CrI})$ of all samples was calculated based on XRD spectra. According to plane 200 at $2 \theta$ $=21^{\circ}$ in all sample asymmetric, the CrI of each sample was escalated as the temperature increase. The raw EFB has the lowest value, which is $54.83 \%$, influenced by the presence of lignocellulose in the EFB structure. Residue fiber obtained after lignin extraction was characterized, as depicted in Figures 6,7 and 8. The sample that undergoes reaction at the highest temperature has a high degree of crystallinity, which is $70 \%$. Based on Table 2, the crystallinity index of each samples different due to the structure of amorphous or crystalline. Consequently, it indicated that there was a high amount of removal of lignin. Meanwhile, $\mathrm{CrI}$ of the sample extracted at $80^{\circ} \mathrm{C}$ decreasing continuously from $64.28 \%$ to $55.42 \%$. The lowest compared to others proven there was cellulose removal, which contributes to a low crystalline degree of residue EFB. The XRD pattern exhibit in a broad peak describes the amorphous structure [17].

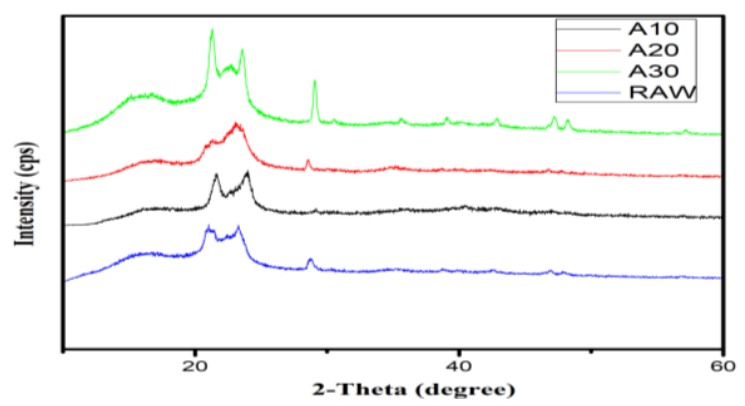

Figure 6. XRD graph of EFB residue (A10): $80^{\circ} \mathrm{C} 10 \mathrm{~min}(\mathrm{~A} 20): 80^{\circ} \mathrm{C} 20 \mathrm{~min}(\mathrm{~A} 30): 80^{\circ} \mathrm{C} 30 \mathrm{~min} \mathrm{RAW}$ : Raw EFB 


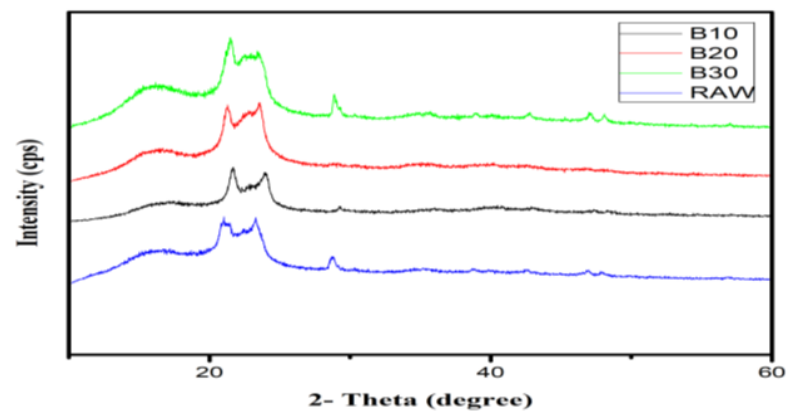

Figure 7. XRD graph of EFB residue (B10):90 ${ }^{\circ} \mathrm{C} 10 \min (\mathrm{B} 20): 90{ }^{\circ} \mathrm{C} 20 \mathrm{~min}(\mathrm{~B} 30): 90{ }^{\circ} \mathrm{C} 30 \mathrm{~min} \mathrm{RAW}$ : Raw EFB

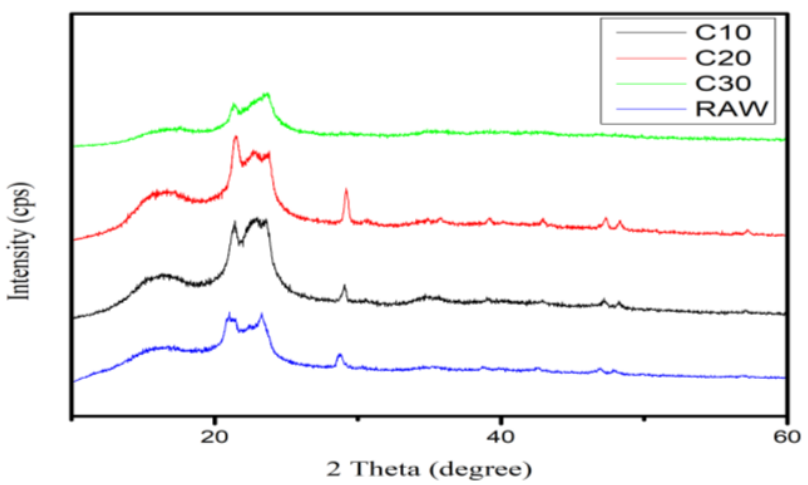

Figure 8. XRD graph of EFB residue (C10):100 ${ }^{\circ} \mathrm{C} 10 \min (\mathrm{C} 20): 100{ }^{\circ} \mathrm{C} 20 \min (\mathrm{C} 30): 100{ }^{\circ} \mathrm{C} 30 \mathrm{~min} \mathrm{RAW}$ : Raw EFB

Table 2. Crystallinity index of raw EFB and residue fiber

\begin{tabular}{llll}
\hline Sample & $\mathrm{I}_{\mathrm{am}}$ & $\mathrm{I}_{200}$ & $\mathrm{CrI}(\%)$ \\
\hline Raw EFB & 787.26 & 1742.91 & 54.83 \\
C30 & 243.53 & 830.40 & 70.00 \\
C20 & 262.14 & 855.33 & 69.35 \\
C10 & 255.60 & 823.10 & 68.95 \\
B30 & 406.19 & 1272.59 & 67.92 \\
B20 & 406.17 & 1247.54 & 67.44 \\
B10 & 627.07 & 1871.11 & 66.49 \\
A30 & 869.10 & 2433.15 & 64.28 \\
A20 & 795.47 & 1949.69 & 59.20 \\
A10 & 402.67 & 903.29 & 55.42 \\
\hline
\end{tabular}

\section{CONCLUSION}

A convenient DES method via microwave-assisted heating is succeeded extract $30 \%$ lignin from EFB fiber at the highest temperature and time. The amount of lignin yield percentage is affected by those parameters, while the lowest temperature, $80^{\circ} \mathrm{C}$, has a lower percentage of recovered lignin. Thus, the purity of lignin exceeds $80 \%$. Meanwhile, the FTIR spectra have shown the characteristic of lignin in comparison to raw EFB. Besides, on the XRD spectra, there are distinctions of raw EFB thermogram with lignin where consolidation detachment of cellulose and hemicellulose from the reaction. Hence, the amount of cellulose and hemicellulose, also high in the residual fraction based on its value of the crystallinity index has indicated the loss of lignin.

\section{ACKNOWLEDGEMENT}

The authors would like to thank Universiti Malaysia Pahang and Faculty of Industrial Sciences and Technology for the financial support via internal grant RDU190330 and Postgraduate Research Grant Scheme (PGRS1903195). 


\section{REFERENCES}

[1] Watkins, D., et al., Extraction and characterization of lignin from different biomass resources. Journal of Materials Research and Technology, 2015. 4(1): p. 26-32.

[2] Hajirahimkhan, S., C.C. Xu, and P.J. Ragogna, Ultraviolet Curable Coatings of Modified Lignin. ACS Sustainable Chemistry \& Engineering, 2018. 6(11): p. 14685-14694.

[3] Kohli, K., et al., Effective delignification of lignocellulosic biomass by microwave assisted deep eutectic solvents. Bioresource Technology, 2020. 303: p. 122897.

[4] Kumar, A.K., B.S. Parikh, and M. Pravakar, Natural deep eutectic solvent mediated pretreatment of rice straw: bioanalytical characterization of lignin extract and enzymatic hydrolysis of pretreated biomass residue. Environmental Science and Pollution Research, 2016. 23(10): p. 9265-9275.

[5] Liu, Y., et al., Efficient Cleavage of Lignin-Carbohydrate Complexes and Ultrafast Extraction of Lignin Oligomers from Wood Biomass by Microwave-Assisted Treatment with Deep Eutectic Solvent. ChemSusChem, 2017. 10(8): p. 1692-1700.

[6] Passauer, L., et al., Quantitative analysis of the etherification degree of phenolic hydroxyl groups in oxyethylated lignins: correlation of selective aminolysis with FTIR spectroscopy. ACS Sustainable Chemistry \& Engineering, 2016. 4(12): p. 6629-6637.

[7] Oh, Y., et al., Effect of hydrogen bond donor on the choline chloride-based deep eutectic solvent-mediated extraction of lignin from pine wood. International Journal of Biological Macromolecules, 2020. 165: p. 187-197.

[8] Wang, Z.-K., et al., Lewis acid-facilitated deep eutectic solvent (DES) pretreatment for producing high-purity and antioxidative lignin. ACS Sustainable Chemistry \& Engineering, 2019. 8(2): p. 1050-1057.

[9] Jawerth, M., et al., Allylation of a lignin model phenol: a highly selective reaction under benign conditions towards a new thermoset resin platform. RSC advances, 2016. 6(98): p. 96281-96288.

[10] Song, Y., et al., Successive organic solvent fractionation and structural characterization of lignin extracted from hybrid poplar by deep eutectic solvent for improving the homogeneity and isolating narrow fractions. Renewable Energy, 2020.

[11] Becker, H. and L.E. Locascio, Polymer microfluidic devices. Talanta, 2002. 56(2): p. 267-287.

[12] Ufodike, C.O., et al., Evaluation of the inter-particle interference of cellulose and lignin in lignocellulosic materials. International Journal of Biological Macromolecules, 2020. 147: p. 762-767.

[13] Sun, Y.-C., et al., Green process for extraction of lignin by the microwave-assisted ionic liquid approach: Toward biomass biorefinery and lignin characterization. ACS Sustainable Chemistry \& Engineering, 2019. 7(15): p. 13062-13072.

[14] Ramakoti, B., et al., Solvent fractionation of organosolv lignin to improve lignin homogeneity: Structural characterization. Bioresource Technology Reports, 2019. 7: p. 100293.

[15] Yildiz, Z. and S. Ceylan, Pyrolysis of tobacco factory waste biomass. Journal of Thermal Analysis and Calorimetry, 2019. 136(2): p. 783-794.

[16] Ponnusamy, V.K., et al., A review on lignin structure, pretreatments, fermentation reactions and biorefinery potential. Bioresource technology, 2019. 271: p. 462-472.

[17] Pan, M., et al., Physicochemical transformation of rice straw after pretreatment with a deep eutectic solvent of choline chloride/urea. Carbohydrate polymers, 2017. 176: p. 307-314. 